\title{
Üniversite Öğrencilerinin Bilgisayarca Düşünme Becerilerinin Mantıksal Matematiksel Zekâ ve Problem Çözme Becerileri Açısından İncelenmesi*
}

\section{Investigating University Students' Computational Thinking Skills in Terms of Logical Mathematical Intelligence Problem Solving Skills}

\author{
Ali OLUK ${ }^{* *}$ (D) $\quad$ Recep ÇAKIR ${ }^{* * *}$ (iD)
}

Received: 11 November 2017

Research Article

Accepted: 12 March 2019

\begin{abstract}
Although there is no consensus in our country on the concept of Computational Thinking which consists of many sub skills, it has started to attract more interest with recent curriculum studies. This study aimed to explore the relationship between vocational college students' computational thinking skills and their problem solving skills and logical mathematical intelligence self-perceptions by correlational survey method. A total of 237 students (126 females, 111 males) from different departments participated in this study. Computational thinking skill levels scale, logical mathematical intelligence self-perception scale, and problem-solving inventory were used as instruments. ANOVA test was run to examine the difference between departments the skill levels measured. Pearson correlation test was run on the data to investigate the relationships between these skills. As a result of the analyses, it was found that there was a positive significant relationship between the students' computational thinking skills and logical mathematical intelligence problems and problem solving skill levels. As a result of ANOVA analysis; there were significant differences among the departments on computational thinking skills and logical mathematical intelligence levels, but it was observed that problem-solving skills were not significant differences among the departments.
\end{abstract}

Keywords: computational thinking, problem solving, logical mathematical intelligence.

ÖZ: İçerisinde birçok alt becerisi kapsayan bilgisayarca düşünme (Computational Thinking) kavramı ülkemiz için henüz bir kavram birliğine ulaşılamamış olsa da son yapılan müfredat çalışmaları ile daha fazla dikkat çekmeye başlamıştır. $\mathrm{Bu}$ çalışmada ilişkisel tarama modeli kullanılarak meslek yüksekokulu öğrencilerinin bilgisayarca düşünme becerileri ile problem çözme becerisi ve mantıksal matematiksel zekâ özalgıları arasındaki ilişkinin incelenmesi hedeflenmiştir. Çalışmaya farklı bölümlerden 126 kız 111 erkek toplam 237 öğrenci katılmıştır. Bilgisayarca düşünme beceri düzeyleri, mantıksal matematiksel zekâ özalgı ölçeği ve problem çözme envanterinin kullanıldığı çalışmada bölümler arası farklılığı incelemek için ANOVA testi uygulanmıştır. Bu beceriler arasındaki ilişkiyi incelemek için verilere Pearson Korelason testi uygulanmıştır. Yapılan analizler sonucunda öğrencilerin bilgisayarca düşünme becerileri ile mantıksal matematiksel zeka özalgıları ve problem çözme beceri düzeyleri arasında pozitif yönde anlamlı bir ilişki olduğu bulunmuştur. Yapılan ANOVA analizleri sonucunda; bilgisayarca düşünme beceri ve mantıksal matematiksel zeka düzeyleri değişkenlerinin bölümler arasında anlamlı farklılıklar gösterdiği, fakat problem çözme becerilerinin bölümler arasında anlamlı bir farklılık olmadığı görülmüştür.

Anahtar kelimeler: bilgisayarca düşünme, problem çözme, mantıksal matematiksel zekâ.

\footnotetext{
${ }^{*}$ A part of this study was presented at the ICITS Symposium 2017 on 25 May 2017.

Corresponding Author: Lecturer, Kastamonu University, Kastamonu, Turkey, alioluk85@gmail.com, https://orcid.org/0000-0002-2246-7563

*** Assoc. Prof. Dr., Amasya University, Amasya, Turkey, recepcakir@gmail.com, https://orcid.org/0000-0002-26415007
}

Citation Information

Oluk, A., \& Çakır, R. (2019). Üniversite öğrencilerinin bilgisayarca düşünme becerilerinin mantıksal matematiksel zekâ ve problem çözme becerileri açısından incelenmesi. Kuramsal Ĕgitimbilim Dergisi [Journal of Theoretical Educational Science], 12(2), 457-473. 


\section{Giriş}

Her geçen y1l öğrencilerden beklenen beceriler değişmekte ya da yeni beceriler eklenmekte olduğu söylenebilir. 21. Yüzyıl öğrencilerinden beklenen becerilerden biride bilgisayarca düşünme (Computational Thinking) becerisidir (Wing, 2006). ISTE (International Society for Technology in Education)'nin yayınladığı öğrenci standartları başlıklarından biride "bilgisayarca düşünme" olduğu görülmektedir (ISTE, 2016). Bilgisayarca düşünme kavramının popüler hale gelmesi Wing (2006)'in temel bilgisayar bilimleri 1şı̆̆ında problem çözme, sistem tasarlama ve insan davranışlarını anlamaya çalışmak olarak ifade etmesi ile meydana gelmiştir. Bilgisayarca düşünme için yapılan bir başka tanımda ise günlük hayatta karşılaştığımız problemlerin çözümleri için bilgisayarı üretim aracı olarak kullanabilmek için lazım olan bilgi, beceri ve tutumlar olarak ifade edilmiştir (Özden, 2016). ISTE (2015), bilgisayarca düşünmeyi algoritmik düşünme, yaratıcı düşünme, eleştirel düşünme, işbirlikli öğrenme ve iletişim becerileri gibi alt becerileri olmadan tam olarak ifade edilemeyeceğini söylemektedir. Bu çerçevede bilgisayarca düşünmeyi daha iyi anlayabilmek için bu alt becerileri anlamanın önemli bir yeri olduğu söylenebilir.

Şekil 1. Bilgisayarca Düşünme Becerisi Alt Becerileri (ISTE, 2015)

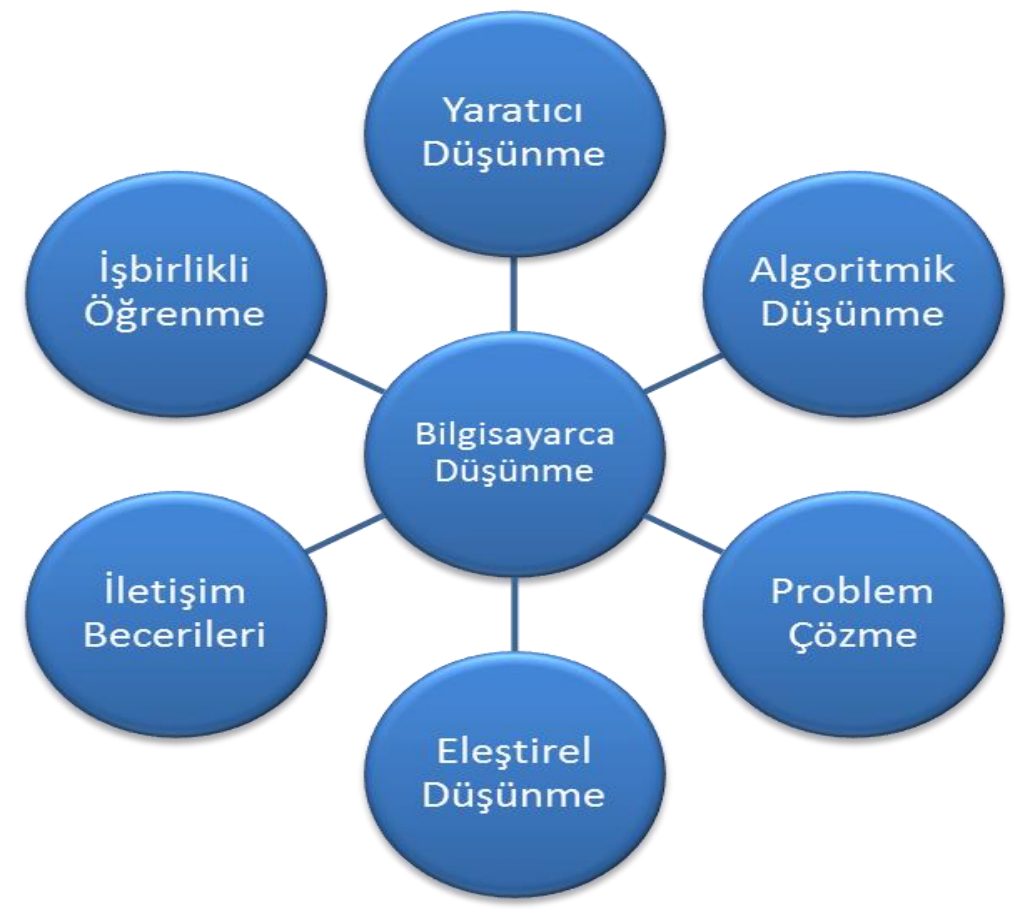

Bir problemin çözümü için basamaklı olarak planlanan işlemlere algoritma olarak ifade edilebilir. Algoritmik düşünme ise bir problemin çözümü için bireylerin fikir alışverişinde bulunmalarına imkân veren bir düşünme biçimi olarak tanımlanmaktadır (Kayama ve diğerleri, 2014). Bilgisayarca düşünmenin önemli bir bileşeni olarak ifade edilen algoritmik düşünme (Basu, 2016; ISTE, 2015; Korkmaz, Çakır, \& Özden, 2017), veri işleme ve adım adım problem çözümü oluşturması gibi bazı yönleri ile bilgisayarca düşünme tanımına benzer yönleri bulunduğu düşünülebilir.

Bilgisayarca düşünmenin bir diğer alt becerisi ise problem çözme becerisidir. Problem çözme bilinen kuralların uygulanması yerine yeni çözüm yolları bulmaya 
çalışmak olarak tanımlanabilir (Korkut, 2002). Problem çözme becerisi sayesinde bireylerin karşılaştıkları problemler karşısında bilgi ve yeteneklerini kullanma ve geliştirmeleri sağlanabilir (Erden \& Akman, 2004). Bu nedenle eğitim sistemlerinde problem çözme becerisini geliştirmek önemli bir amaç olarak belirtilmektedir (Koray \& Azar, 2008).

Bilgisayarca düşünme için önemli bir bileşen ise yaratıcı düşünme ya da yaratıcılık olduğu söylenebilir. Yaratıcılık birey ya da bireylerin yeni ve yararlı bir bilgiyi elde etmek için yetenekler, süreçler ve çevre ile etkileşimi olarak tanımlanmaktadır (Plucker, Beghetto, \& Dow, 2004). Yaratıcılık sonradan kazanılacak bir beceri olmakla birlikte doğuştan bu beceriye sahip olan bireylerde daha yüksek seviyede olduğu düşünülmektedir (Sümbül, 2007). $\mathrm{Bu}$ sebeple bütün eğitim basamaklarında yaratıcılığı geliştirecek tür programlara yer verilmelidir (Özden, 2014).

ISTE (2015), bilgisayarca düşünme için belirlemiş olduğu diğer bir alt beceri ise eleştirel düşünmedir. Eleştirel düşünme problemlerin doğru sonuca ulaşması için yapılan araştırmalar olarak tanımlanmıştır (Kurfiss, 1988). Eleştirel düşünmeyi kullanabilen öğrenciler problemi çözmek için gerekli sorgulamayı yapar, çözüm için gerekli bilgiyi bulup bu bilgi ile geliştirmiş olduğu çözüm yollarını test ederek güvenilir sonuçlar elde edebilirler (Ocak, \& Develi-Topal, 2010). Bilgisayarca düşünme ile eleştirel düşünme benzer özellikleri olmakla birlikte aynı olmadıkları söylenebilir. Nitekim bilgisayarca düşünme eleştirel düşünmeyi de kapsayan bir düşünme biçimidir (Barr, Harrison, \& Conery, 2011).

İşbirlikli öğrenme bireysel ve grup halinde öğrenmelerin üst düzeye çıkarılması için tercih edilebilecek bir öğrenme yöntemi olarak tanımlanmaktadır (Veenman, Benthum, Bootsma, Dieren, \& Kemp, 2002). Tüm alanlar için tercih edilebilecek bir öğrenme yöntemi olan (Timuçin, 2010) işbirlikli öğrenme sayesinde öğrenciler üst düzeyde öğrenme gerçekleştirirken arkadaşlarına da bilgi aktarmaları beklenmektedir (Doymuş, Şimşek, \& Bayrakçeken, 2004).

Bilgisayarca düşünmenin diğer bir bileşeni olan iletişim becerileri gönderen ile alıcı olan kişi arasında bilginin aktarılma süreci olarak ifade edilebilir. Bireyler çevreleri ile etkili biçimde iletişim kurmak ve kendilerini ifade etmek ve istendik değişimleri sağlayabilmek için iletişim becerilerine ihtiyaç duymaktadırlar (Gökçe \& AtanurBaşkan, 2012).

Yukarıda yer alan becerilere bakıldığında aslında bunların eğitim sistemleri ile öğrencilere kazandırılması hedeflenen en önemli becerilerin içerisinden yer aldığı söylenebilir. $\mathrm{Bu}$ becerilerin tümünü içerisinde barındıran bilgisayarca düşünme becerisinin önemi ise gün geçtikçe daha fazla anlam kazanmaya başlandiğ bilinmektedir (Grover \& Pea, 2013; León \& Robles, 2015; Voogt, Fisser, Good, Mishra, $\&$ Yadav, 2015). Son yıllarda ülkelerin mevcut müfredat çalışmalarına bilgisayarca düşünme becerilerini eklemek için çalışmalar yaptıkları görülmektedir (Department For Education, 2013; MEB, 2017; The Collage Board, 2016).

Bilgisayarca düşünme bilgisayar kullanarak öğrencilerin problem çözme kapasitesini artırmak, mantıklı düşünme ve eleştirel düşünme gibi becerilerini ön plana çıkarmayı hedeflemektedir (Korkmaz, Çakır, Özden, Oluk, \& Sarığlu, 2015). Fakat bilgisayarca düşünme sadece insan bilgisayar etkileşimi değil çok daha fazlasını ifade etmektedir (Mishra \& Yadav, 2013). Nitekim bilgisayarca düşünme sadece bilgisayar 
bilimi ile ilgilenenlerin değil herkesin kazanması gereken bir düşünme biçimi olarak ifade edilmektedir (Korkmaz, Çakır, \& Özden, 2015; Yadav, Mayfield, Zhou, Hambrusch \& Korb, 2014). Bu düşünme biçimi ile öğrencilerin sorunları tanıyan, problem çözme sürecine hâkim ve problemlere daha verimli bir şekilde çözüm üreten bireyler yetiştirilmesi hedeflenmektedir (Czerkawski \& Lyman, 2015). Mishra ve Yadav (2013), bilgisayarca düşünme sayesinde öğrencilerin teknoloji tüketicisi bireyler olmaktan kurtulup üretici ve yaratıcı bir yöne yönlendirilebileceğini düşünmektedir.

Bilgisayarca düşünme konusunun son zamanlarda literatürde dikkat çeken çalışmalar arasında yer aldığı görülmektedir. Bu çalışmalarda bilgisayarca düşünme ile problem çözme becerisi arasında ilişkiye değinen çalışmalar da bulunmaktadır (Gonzalez, Gonzalez, \& Fernandez, 2016; Yadav, Zhou, Mayfield, Hambrusch, \& Korb, 2011; Yadav, Hong, \& Stephenson, 2016; Wing, 2010). Wing (2010)'e göre bilgisayarca düşünme matematiksel düşünmeden yararlanmaktadır. Bilgisayarca düşünme problem çözme aşamasında matematiksel düşünme ile ortak yolları kullanmaktadır (Korkmaz, Çakır, \& Özden, 2015). Bu durumda bilgisayarca düşünme ile mantıksal matematiksel zekâ ve problem çözme becerileri arasında bir ilişkiden bahsedilebilir.

Bilgisayarca düşünme becerisinin problem çözme becerisi ile ilişkisini inceleyen çalışmalar olmakla birlikte, bilgisayarca düşünme becerilerinin mantıksal matematiksel zekâ ile problem çözme becerilerinin ilişkisi inceleyen literatürde bir çalışmaya rastlanılmamıştır. 21. yüzyıl becerileri arasında önemli bir yere sahip olduğu düşünülen bu becerilerin bir arada incelenmesi ve aralarındaki ilişkinin ortaya konması açısından yapılan çalışma literatüre önemli bir katkı sağlayacağı düşünülmektedir. Bu çerçevede bu çalışmanın amacı meslek yüksekokulu öğrencilerinin bilgisayarca düşünme düzeylerinin problem çözme ve mantıksal matematiksel zekâ düzeyleri arasında ilişki düzeylerini incelemektir. Çalışmamızın alt problemleri ise şunlardır:

- Öğrencilerin bilgisayarca düşünme becerisi düzeyleri bölümlere göre farklılık göstermekte midir?

- Öğrencilerin mantıksal matematiksel zekâ düzeyleri bölümlere göre farklılık göstermekte midir?

- Öğrencilerin problem çözme becerisi düzeyleri bölümlere göre farklılık göstermekte midir?

- Öğrencilerin Bilgisayarca düşünme becerileri ile problem çözme ve mantıksal matematiksek zekâ düzeyleri arasında ilişki var mıdır?

- Öğrencilerin Bilgisayarca düşünme becerileri cinsiyete göre farklılık göstermekte midir?

\section{Yöntem}

Yapılan çalışmada nicel araştırma yöntemlerinden ilişkisel tarama yöntemi kullanılmıştır. Tarama yöntemi kullanılan araştırmalarda bir grubun belirli özelliklerini belirlemek için verilerin toplanması hedeflenmektedir (Büyüköztürk, Kılıç Çakmak, Akgün, Karadeniz, \& Demirel, 2008). Bu çalışma tarama modellerinden ilişkisel tarama modeli kullanılarak yapılmıştır. İlişkisel tarama modeli iki ya da daha fazla değişkenin aralarındaki ilişkilerin derecesini belirlemek amacı ile yapılan çalışmalar olarak bilinmektedir. İlişkisel tarama modeli değişkenlerin arasındaki ilişkiyi belirlemek amacıyla yapılan araştırma modelidir. 


\section{Evren ve Örneklem}

Çalışmada yer alan öğrenciler Kastamonu Üniversitesi Taşköprü Meslek Yüksekokulu Bilgisayar Programcılı̆̆ı, Bankacılık ve Sigortacılık, İlk ve Acil Yardım ve Tıbbi Dokümantasyon ve Sekterlik bölümü öğrencilerinden oluşmaktadır. Çalışmaya 126 kız 111 erkek öğrenci olmak üzere toplam 237 öğrenci katılmıştır. Bölümlerdeki öğrencilerin cinsiyete göre dağılımları tablo 1'de verilmiştir.

Tablo 1

Bölümlerdeki Öğrencilerin Cinsiyete Göre Dă̆ılımları

\begin{tabular}{|c|c|c|c|c|c|}
\hline \multirow{3}{*}{ Bölüm } & \multicolumn{5}{|c|}{ Cinsiyet } \\
\hline & \multicolumn{2}{|l|}{$\mathrm{K} 1 \mathrm{z}$} & \multicolumn{2}{|l|}{ Erkek } & \multirow{2}{*}{$\begin{array}{l}\text { Toplam } \\
n\end{array}$} \\
\hline & $n$ & $\%$ & $n$ & $\%$ & \\
\hline Bilgisayar Programcillğ 1 & 20 & 41.7 & 28 & 58.3 & 48 \\
\hline Bankacılık ve Sigortacılık & 30 & 57.7 & 22 & 42.3 & 52 \\
\hline İlk ve Acil Yardım & 44 & 54.3 & 37 & 45.7 & 81 \\
\hline Tıbbi Dokümantasyon ve Sekterlik & 32 & 54.3 & 24 & 45.7 & 56 \\
\hline Toplam & 126 & 53.2 & 111 & 46.8 & 237 \\
\hline
\end{tabular}

\section{Veri Toplama Araçları}

Veri toplama aracı olarak öğrencilere Bilgisayarca Düşünme Beceri Düzeyleri Ölçeği, Mantıksal Matematiksel Zekâ Özalgı Ölçeği ve Problem Çözme Envanteri kullanılmıştır. Bu ölçekler incelendiğinde ölçeklerin üniversite öğrencilerine yönelik geliştirildikleri ve gerekli geçerlilik ve güvenirlilik çalışmalarının yapıldı̆̆ görülmektedir. $\mathrm{Bu}$ nedenle çalışma kapsamında bu ölçeklerin kullanılmasına karar verilmiştir.

Bilgisayarca Düşünme Beceri Düzeyleri Ölçeği: Bilgisayarca düşünme beceri düzeyleri ölçeği Korkmaz, Çakır ve Özden (2017) tarafından geliştirilmiş olup 5'li Likert tipte, 5 faktör ve 29 maddeden oluşmaktadır. Ölçek üniversite öğrencilerinin bilgisayarca düşünme beceri düzeylerini ölçmek için geliştirilmiştir. Ölçeğin gerekli analizleri yapılmış Cronbach Alpha iç güvenirlilik katsayısı .822 olarak hesaplanmıştır. Çalışma kapsamında toplanan veriler ile yapılan analizler sonucu ölçeğin Cronbach Alpha iç güvenirlilik kaysayısı .45 olarak hesaplanmıştır.

Mantıksal - Matematiksel Zekâ Özalgı Ölçeği: Mantıksal - Matematiksel zekâ ölçeği Yeşil ve Korkmaz (2010) tarafindan geliştirilen Çoklu Zekâ Algi ölçeği içerisinde geliştirilen bir alt ölçektir. Ölçek 5'li Likert tip ve 21 maddeden oluşmaktadır. Mantıksal Matematiksel Zekâ Özalgı ölçeği iki faktöre ayrılmakta ve birinci faktörde kendi içerisinde iki faktöre ayrılmaktadır. Dolayısı ile ölçek matematiksel transfer, matematiksel ilişki ve mantıksal ilişki olmak üzere üç faktörden oluşmaktadır. Ölçeğin toplan Cronbach Alpha iç güvenirlilik katsayısı .925 olarak hesaplanmıştır. Bu çalışma kapsamında toplanan veriler ile yapılan analiz sonucu ölçeğin Cronbach Alpha iç güvenirlilik kaysayısı ise .594 olarak hesaplanmıştır. 
Problem Çözme Envanteri: Problem çözme envanteri Heppner ve Peterson tarafından 1982 yılında geliştirilmiş olup 1990 yılında Taylan tarafından ülkemiz için güvenirlik çalışması yapılmıştır. Bu Envanter, problem çözme aşamalarını belirleyen, kişilerin kendi sorun çözme davranışları ve yaklaşımları hakkında ne düşündüklerini değerlendirmek amacıyla geliştirilmiş bir araçtır. Ölçeğin iç tutarlılık katsayısı 0.86 olarak hesaplanmıştır (Taylan, 1990: Akt. Öztürk Can, Öner, Çelebi 2009). Ölçek 6 puanlı Likert tipinde 35 maddeden oluşmaktadır. Ölçek Problem Çözmeye İnanç, Kaçınma ve Kişisel Kontrol olmak üzere 3 faktörden oluşmaktadır. Öğrencilerden toplanan veriler analiz edildiğinde ölçeğin Cronbach Alpha iç güvenirlilik katsayısı .673 olarak hesaplanmıştır.

\section{Verilerin Analizi}

Verilerin analizi için SPSS istatistik programı kullanılmıştır. Verilerin analizinde kullanılacak yöntemlerin belirlenmesi için yapılan analiz sonucunda verilerin normal dağılım gösterdiği tespit edilmiştir. Öğrencilerin bilgisayarca düşünme becerileri, mantıksal matematiksel zekâ özalgısı ve problem çözme becerisinin bölümlere göre farklılığını test etmek için ANOVA analizi kullanılmıştır. Verilerin cinsiyet değişkenine göre farklılığını incelemek için ise bağımsız örneklem t-testi uygulanmıştır.

\section{Bulgular}

\section{Bilgisayarca Düşünme Beceri Düzeylerinin Bölümlere Göre Farklılığı}

Bölümlerde yer alan öğrencilerin bilgisayarca düşünme beceri düzeyleri arasında anlamlı bir farklılık olup olmadığını anlamak için bilgisayarca düşünme beceri düzeyleri ölçeği ile toplanan verilere ANOVA testi uygulanmıştır. Test sonucu elde edilen veriler Tablo 2'de verilmiştir.

Tablo 2

Bilgisayarca Düşünme Beceri Düzeylerinin Bölümlere Göre ANOVA Sonuçları

\begin{tabular}{|c|c|c|c|c|c|c|c|}
\hline \multicolumn{3}{|l|}{ Sinıflar } & \multicolumn{3}{|c|}{$\bar{X}$} & \multicolumn{2}{|r|}{ SS } \\
\hline \multicolumn{3}{|c|}{ Bilgisayar Programcılığı } & 48 & \multicolumn{2}{|c|}{70.43} & & 11.33 \\
\hline \multicolumn{3}{|c|}{ Bankacılık ve Sigortacılık } & 52 & \multicolumn{2}{|c|}{66.74} & & 8.56 \\
\hline \multicolumn{3}{|c|}{ İlk ve Acil Yardım } & 81 & \multicolumn{2}{|c|}{69.96} & & 8.89 \\
\hline \multicolumn{3}{|c|}{ Tibbi Dokümantasyon ve Sekterlik } & 56 & \multicolumn{2}{|c|}{65.68} & & 7.79 \\
\hline \multirow[t]{2}{*}{ Toplam } & & & 237 & \multicolumn{2}{|c|}{68.34} & & 9.30 \\
\hline & $\begin{array}{l}\text { Kareler } \\
\text { Toplam }\end{array}$ & \multicolumn{2}{|l|}{ sd } & \multicolumn{2}{|c|}{$\begin{array}{c}\text { Kareler } \\
\text { Ortalaması }\end{array}$} & \multicolumn{2}{|l|}{$\mathrm{p}$} \\
\hline Gruplararası & 953.473 & \multicolumn{2}{|l|}{3} & \multicolumn{2}{|l|}{317.824} & \multicolumn{2}{|l|}{.011} \\
\hline Gruplariçi & 19438.032 & 233 & & \multicolumn{2}{|l|}{83.425} & & \\
\hline Toplam & 20391.505 & 236 & & & & & \\
\hline
\end{tabular}

Tablo 2'de görüldüğü gibi bilgisayarca düşünme beceri düzeyi en yüksek ortalamaya ( $\bar{X}=70.43)$ sahip olan bölüm bilgisayar programcılığıdır. Bu bölümü sırası ile 
ilk ve acil yardım bölümü ( $\bar{X}=69.96)$, bankacılık ve sigortacılık bölümü $(\bar{X}=66.74)$ ve tıbbi dokümantasyon ve sekreterlik bölümü $(\bar{X}=65.68)$ izlemektedir.

Yapılan ANOVA analizi sonucunda bölümlerin bilgisayarca düşünme beceri düzeyleri arasında istatistiksel olarak anlamlı bir fark bulunmakta olduğu görülmektedir $(\mathrm{F}(3,233)=3.810, p<.05)$. Analiz sonucunda bilgisayar programc1lığı bölümü ile tıbbi dokümantasyon ve sekreterlik bölümü arasında ve ilk acil yardım bölümü ile tıbbi dokümantasyon ve sekreterlik bölümü arasında anlamlı farklılık olduğu görülmektedir.

\section{Problem Çözme Beceri Düzeyleri Bölümlere Göre Farklılığı}

Bölümlerde yer alan öğrencilerin problem çözme beceri düzeyleri arasında anlamlı bir farklılık olup olmadığını anlamak için problem çözme envanteri ile toplanan verilere ANOVA testi uygulanmıştır. Test sonucu elde edilen veriler Tablo 3'de verilmiştir.

Tablo 3

Problem Çözme Beceri Düzeylerinin Bölümlere Göre ANOVA Sonuçları

\begin{tabular}{|c|c|c|c|c|c|c|}
\hline Sinıflar & & $\mathrm{N}$ & $\bar{x}$ & \multicolumn{3}{|c|}{ SS } \\
\hline Bilgisayar Pr & 1liğg & 48 & 64.34 & \multicolumn{3}{|c|}{9.18} \\
\hline Bankacılık v & acilik & 52 & 62.49 & \multicolumn{3}{|c|}{8.31} \\
\hline İlk ve Acil Y & & 81 & 62.56 & \multicolumn{3}{|c|}{6.80} \\
\hline Tibbi Doküm & on ve Sekterlik & 56 & 62.93 & \multicolumn{3}{|c|}{7.05} \\
\hline \multirow[t]{2}{*}{ Toplam } & & 237 & \multicolumn{2}{|c|}{62.99} & \multicolumn{2}{|r|}{7.71} \\
\hline & $\begin{array}{l}\text { Kareler } \\
\text { Toplamı }\end{array}$ & sd & $\begin{array}{c}\text { Kareler } \\
\text { Ortalaması }\end{array}$ & $\mathrm{F}$ & $\mathrm{p}$ & \\
\hline Gruplararası & 115.230 & 3 & 38.410 & .643 & \multicolumn{2}{|r|}{.588} \\
\hline Gruplariçi & 13915.523 & 233 & 59.723 & & & \\
\hline Toplam & 14030.753 & 236 & & & & \\
\hline
\end{tabular}

Tablo 3'de görüldüğü gibi problem çözme beceri düzeyi en yüksek ortalamaya $(\bar{X}=64.34)$ sahip olan bölüm bilgisayar programcılığıdır. Bu bölümü sırası ile tıbbi dokümantasyon ve sekreterlik bölümü ( $\bar{X}=62.93)$, ilk ve acil yardım bölümü $(\bar{X}=62.56)$ ve bankac1lık ve sigortac1lık ( $\bar{X}=62.49)$ bölümü izlemektedir.

Yapılan ANOVA analizi sonucunda bölümlerin bilgisayarca düşünme beceri düzeyleri arasında istatistiksel olarak anlamlı bir fark bulunmadığı görülmektedir ( F (3, $233)=.643, p>.05)$. 


\section{Mantıksal Matematiksel Zekâ Düzeyleri Bölümlere Göre Farklılığı}

Bölümlerde yer alan öğrencilerin mantıksal matematiksel zekâ düzeyleri arasında anlamlı bir farklılık olup olmadığını anlamak için mantıksal - matematiksel zekâ özalgı ölçeği ile toplanan verilere ANOVA testi uygulanmıştır. Test sonucu elde edilen veriler Tablo 4'te verilmiştir.

Tablo 4

Mantıksal Matematiksel Zekâ Düzeylerinin Bölümlere Göre ANOVA Sonuçları

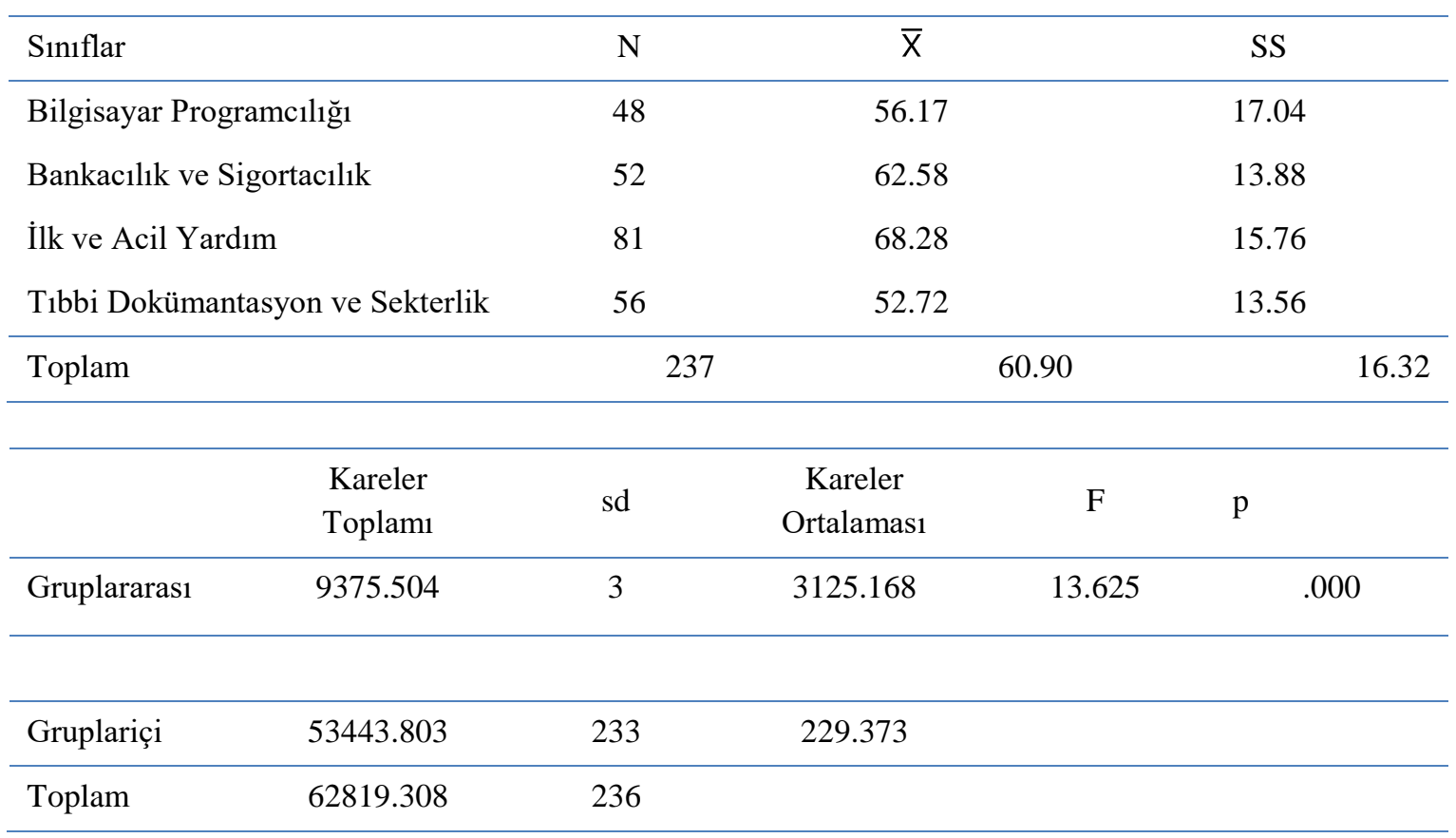

Tablo 4'te görüldüğü gibi mantıksal matematiksel zekâ düzeyi en yüksek ortalamaya $(\overline{\mathrm{X}}=68.28)$ sahip olan bölüm ilk ve acil yardım bölümüdür. Bu bölümü sıras1 ile bankacılık ve sigortacılık bölümü $(\bar{X}=62.58)$, bilgisayar programc1lığ1 bölümü $(\bar{X}=56.17)$ ve tıbbi dokümantasyon ve sekreterlik bölümü $(\bar{X}=52.72)$ izlemektedir.

Yapılan ANOVA analizi sonucunda bölümlerin mantıksal matematiksel zekâ düzeyleri arasında istatistiksel olarak anlamlı bir farklılık olduğu görülmektedir ( $\mathrm{F}(3$, $233)=13.625, p<.01)$. Analiz sonucu bu farkın ilk acil yardım - bilgisayar programcılığı, ilk acil yardım - tıbbi dokümantasyon ve sekreterlik ve bankacılık - tıbbi dokümantasyon ve sekreterlik bölümler arasında olduğu görülmektedir.

\section{Öğrencilerin Bilgisayarca Düşünme Becerileri ile Problem Çözme ve Mantıksal - Matematiksel Zekâ Düzeyleri Arasında İlişkisi}

Öğrencilerin Bilgisayarca düşünme becerileri ile problem çözme ve mantıksal matematiksel zekâ düzeyleri arasında anlamlı bir farklılık olup olmadığını anlamak için verilere Pearson korelasyon katsayısı testi uygulanmıştır. Test sonucu elde edilen veriler Tablo 5 'te verilmiştir. 
Tablo 5

Öğrencilerin Bilgisayarca Düşünme Becerileri ile Problem Çözme Becerileri ve Mantıksal Matematiksel Zekâ Düzeyleri Arasindaki İlişki

\begin{tabular}{llll}
\hline & & $\begin{array}{l}\text { Bilgisayarca Düşünme } \\
\text { Becerileri }\end{array}$ & $\begin{array}{l}\text { Problem Çözme } \\
\text { Becerileri }\end{array}$ \\
\hline $\begin{array}{l}\text { Bilgisayarca Düşünme } \\
\text { Becerileri }\end{array}$ & Pearson Correlation & 1 & .430 \\
& $\mathrm{P}$ & & .000 \\
& $\mathrm{~N}$ & 237 & 237 \\
\hline & & Bilgisayarca Düşünme & Mantıksal - \\
& & Becerileri & Matematiksel Zeka \\
\hline $\begin{array}{l}\text { Bilgisayarca Düşünme } \\
\text { Becerileri }\end{array}$ & Pearson Correlation & 1 & .522 \\
& $\mathrm{P}$ & & .000 \\
& $\mathrm{~N}$ & 237 & 237 \\
\hline
\end{tabular}

Tablo 5'te yer alan veriler incelendiğinde öğrencilerin bilgisayarca düşünme beceri düzeyleri ile problem çözme beceri düzeyleri arasında pozitif yönde, orta düzeyde ve anlamlı bir ilişkinin olduğu görülmektedir $(r=0.430 ; p<0.05)$. Öğrencilerin bilgisayarca düşünme beceri düzeyleri ile mantıksal matematiksel zekâ düzeyleri arasında pozitif yönde, orta düzeyde ve anlamlı bir ilişkinin olduğu görülmektedir $(r=0.522 ; p<0.05)$.

\section{Öğrencilerin Bilgisayarca Düşünme Becerileri Cinsiyete Göre Farklılı̆̆ı}

Öğrencilerin bilgisayarca düşünme beceri düzeyleri arasında cinsiyete göre anlamlı bir farklılık olup olmadığını anlamak için bilgisayarca düşünme beceri düzeyleri ölçeği ile toplanan verilere bağımsız örneklem t-testi (independent sample t-test) uygulanmıştır. Test sonucu elde edilen veriler Tablo 6' da verilmiştir.

Tablo 6

Bilgisayarca Düşünme Beceri Düzeylerinin Cinsiyete Göre T-Testi Sonuçları

\begin{tabular}{lllllll}
\hline Cinsiyet & $\mathrm{N}$ & $\overline{\mathrm{X}}$ & $\mathrm{SS}$ & $\mathrm{sd}$ & $\mathrm{t}$ & $\mathrm{p}$ \\
\hline $\mathrm{K} 1 \mathrm{z}$ & 126 & 67.68 & 9.08 & 235 & 1.152 & .251 \\
Erkek & 111 & 69.08 & 9.52 & & & \\
\hline
\end{tabular}

Tablo 6'da yer alan veriler incelendiğinde kız öğrencilerin bilgisayarca düşünme becerileri ortalamasının $(\bar{X}=67.68)$ erkek öğrencilerin ortalamasına $(\bar{X}=69.08)$ göre daha düşük olduğu görülmektedir. Fakat aradaki bu fark istatistiksel olarak anlamlı bir farkl11.k ifade etmemektedir. $(\mathrm{t}(235)=1.152 ; p>0.05)$.

\section{Sonuç ve Tartışma}

Bilgisayarca düşünme becerisinin öğrencilerin problem çözme becerilerini geliştirme hususunda yardımcı olacağı düşünülmektedir (Yadav, Hong, \& Stephenson, 2016). Problem çözme becerisinin ise matematik yolu ile geliştirilebilecek temel 
becerilerden biri olduğu bilinmektedir (Olkun, Şahin, Akkurt, Dikkartın, \& Gülbağc1, 2009). Bilgisayarca düşünme matematiksel düşünme ile ilişkili fakat aynı değildir (Barr, Harrison, \& Conery, 2011). Her iki düşünme biçimi de temel bir dil yapısına ve problem çözme için modellerle soyutlama yöntemini kullanmaktadır (Basu, 2016). Bu çalışmada meslek yüksekokulu öğrencilerinin bilgisayarca düşünme düzeylerinin problem çözme ve mantıksal matematiksel zekâ düzeyleri arasında ilişki incelenmiştir.

Çalışma sonuçlarına göre bölümlerin bilgisayarca düşünme düzeylerinin birbirinden farklı olduğu görülmektedir. Bu fark istatistiksel olarak bir anlam ifade etmekle birlikte en yüksek bilgisayarca düşünme beceri seviyesi bilgisayar programcılığı öğrencilerine aittir. Araştırmaya katılan bölümler içerisinden bilgisayar programlama eğitimi alan tek bölümün bilgisayar programcılı̆̆ı bölümü olduğu bilinmektedir. $\mathrm{Bu}$ durum bilgisayarca düşünmenin alt becerilerini kazandırmak için programlama eğitiminin önemli bir yere sahip olması ile ifade edilebilir (Akpınar \& Altun, 2014; Bers ve ark., 2014; Ioannou \& Angeli, 2016; Karabak \& Güneş 2013; Shin, Park, \& Bae, 2013; Oluk \& Korkmaz, 2016). Bers ve arkadaşlarının (2014) yaptıkları çalışmada öğrencilerine robot programlama eğitimi verdikleri ve bu eğitimin bilgisayarca düşünme becerisi geliştirmede olumlu etkisi olduğu bilinmektedir. Oluk ve Korkmaz (2016) ise yaptıkları çalışmada bilgisayarca düşünme becerisi ile programlama eğitimi arasında yüksek seviyede anlamlı bir ilişki olduğuna değinmişlerdir. Yapılan bir başka çalışmada ise öğrenciler için hazırlanmış bir programlama aracı ile yapılan çalışmada aracın öğrencilerin bilgisayarca düşünme becerileri öğrenme güçlüklerini azalttığı ve becerinin gelişmesine olumlu katkı yaptığı bilinmektedir (Chen, Shen, Barth-Cohen, Jiang, Huang, \& Eltoukhy, 2017). Yadav ve arkadaşları (2011) yaptıkları çalışma ile bilgisayar bilimleri eğitiminin bilgisayarca düşünmeyi genel olarak arttırdığı yönünde bir sonuca ulaşmışlardır. Bizim çalışmamızda bu görüşleri destekler niteliktedir.

$\mathrm{Bu}$ çalışmanın diğer bir sonucu da, bölümlerin problem çözme beceri düzeylerinin birbirinden farklı olmasına rağmen aradaki fark istatistiksel olarak bir anlam ifade etmemesidir. Bölümler arasında problem çözme beceri düzeyi en yüksek ortalama bilgisayar programcılığ bölümüne aittir. Bu duruma bilgisayar programcılığ öğrencilerinin aldıkları programlama eğitiminin etkisi olduğu söylenebilir. Literatürde yapılan çalışmalara bakıldığında programlama eğitiminin problem çözme becerilerini geliştirmede olumlu etkiye sahip olduğu sonucuna ulaşılan çalışmalar olduğu bilinmektedir (Calder, 2010; Fessakis, Gouli, \& Mavroudi, 2013).

Çalışmada ortaya çıkan bir diğer sonuca göre, bölümlerin mantıksal matematiksel zekâ özalgı düzeyleri ortalamaları birbirinden farklı olmakla birlikte bu fark istatistiksel olarak bir anlam ifade etmektedir. Bölümlerin mantıksal matematiksel zekâ özalgı düzeylerinden en yüksek ortalamaya sahip bölüm İlk ve Acil Yardım Bölümüdür. En düşük ortalamaya sahip bölüm ise Tibbi Dokümantasyon ve Sekreterlik bölümüdür. Bölümlerin üniversite yerleştirme puanlarına bakıldığında tıbbi dokümantasyon ve sekreterlik bölümünün sözel puan türü ile yerleşen tek bölüm olduğu görülmektedir. En yüksek yerleştirme puanına sahip bölümün ise ilk ve acil yardım bölümü olduğu görülmektedir. Mantıksal matematiksel zekâ ile matematik akademik başarı arasındaki ilişkinin belirtildiği çalışmalar bulunmaktadır (Barcelos \& Silveira, 2012; Liu \& Wang, 2010). Mantıksal Matematiksel zekâ özalgılarının farklı olması bu durumla açıklanabilir. 
Öğrencilerin bilgisayarca düşünme beceri düzeyleri ile problem çözme beceri düzeyleri arasında pozitif yönde, orta düzeyde ve anlamlı bir ilişkinin olduğu görülmektedir. Bilgisayarca düşünmenin mantıksal matematiksel zekâ (Barr, Harrison, \& Conery, 2011) ve problem çözme becerisi ile ilişkisi olduğunu ifade eden (Gonzalez, Gonzalez, \& Fernandez, 2016; Yadav, Zhou, Mayfield, Hambrusch, \& Korb, 2011; Yadav, Hong, \& Stephenson, 2016; Wing, 2010) çalışmalar bulunmaktadır. Bilgisayarca düşünmenin karmaşık problemlerin çözümü için sistem tasarlamada matematiksel düşünmeden faydalandığı bilinmektedir (Lu \& Fletscher 2009; Wing 2008; Wing, 2010). Bu durumda bilgisayarca düşünme ile matematiksel düşünmenin bir ilişkisi olduğu düşünülebilir. Bilgisayarca düşünmenin matematiksel düşünme ile ilişkili fakat aynı değildir (Barr, Harrison, \& Conery, 2011). Bilgisayarca düşünme ile problem çözme becerisinin ilişkisini ortaya koymak için Gonzalez ve arkadaşları (2016) yaptıkları çalışmada problem çözme ile bilgisayarca düşünmenin ilişkili olduğu sonucuna varmışlardır. Bizim yaptığımız çalışmada bu görüşleri destekler niteliktedir.

Son olarak, çalışma sonuçlarına göre, öğrencilerin bilgisayarca düşünme beceri düzeylerinin cinsiyete göre erkek öğrencilerinin lehine bir farklılık göstermektedir. Fakat bu fark istatistiksel olarak bir anlam ifade etmemektedir. Literatürde yapilan çalışmalara bakıldığında bilgisayarca düşünme becerisinin cinsiyet değişkenine göre farklılık göstermediği benzer çalışmalar yer almaktadır (Korkmaz ve ark., 2016; Oluk ve Korkmaz, 2016).

Sonuç olarak yapılan çalışmada öğrencilerin problem çözme becerileri ve mantıksal matematiksel zekâ özalgıları ile bilgisayarca düşünme becerileri arasında bir ilişki olduğu bulunmuştur. Çağımız öğrencileri için önemli bir yere sahip olan bu becerileri kazandırmak için yapılacak olan çalışmalar ve müfredat çalışmalarında ayrı ayrı ele almak yerine bir bütün olarak düşünülerek daha kapsamlı planlamalar yapılabilir. Özellikle programlama ve STEM çalışmalarında öğrencilerle yapılacak etkinlikler planlanırken problem çözme, mantıksal matematiksel zekâ ve bilgisayarca düşünme becerilerini kazandırmak için tüm becerileri kapsayıcı bir planlama yapılması kazanımlar için daha geliştirici olacağı düşünülebilir.

\section{Öneriler}

Araştırma sonucunda elde edilen bulgulara göre araştırmacıların önerileri aşağıda yer almaktadır.

- Üniversite öğrencilerine uygun dersler belirlenerek bilgisayarca düşünme becerileri kazandırılacak etkinlikler yapılabilir.

- Öğrencilerin bilgisayarca düşünme becerileri için geliştirilmiş etkinlikler yapılarak deneysel bir çalışma tasarlanabilir.

- Bu çalışmanın benzeri daha fazla bölüm ve sınıf düzeyi dâhil edilerek tekrarlanabilir. 


\section{Summary}

Purpose and Significance: With each passing year, it can be argued that the skills expected from the students change or new skills are being added. One of the skills that the students of the 21st century are expected to have is Computational Thinking Skills. Computational thinking generally is known as the know-how, skills and attitudes required to utilize computers as a tool for production in solving the problems encountered in daily life. Moreover, it also aims to increase students' problem solving capacity and bring skills such as logical thinking and critical thinking into prominence via the use of computers. Lately, the topic of computational thinking stands out among the studies in literature. As mentioned in literature reviews, computational thinking uses the same methods in Problem Solving step with Logical-Mathematical Thinking. In this framework, this study sought to investigate the relationship between Vocational College students' computational thinking skills and their problem solving skills and logical mathematical intelligence self-perceptions.

Method: Correlational survey model, a quantitative research method, was used in the study. This method is used in the studies conducted to determine the level of relationship between two or more variables. Participating students were composed of Kastamonu University Taşköprü Vocational College computer programming, banking and insurance, first aid and emergency aid and medical documentation and secretarial departments. A total of 237 students (125 females, 111 males) participated in this study. Computational Thinking Skill Levels Scale, Logical Mathematical Intelligence Selfperceptions Scale and Problem Solving Inventory were used to collect data. SPSS statistical package was used to analyze data. The analysis conducted to determine the appropriate methods to be used in data analysis pointed to normal distribution of data; therefore parametric tests were utilized in data analysis.

Results: Based on study results, the department with the highest mean computational thinking skill level ( $\overline{\mathrm{X}}=70.43)$ was found to be department of computer programming followed by first aid and emergency aid department $(\bar{X}=69.96)$, banking and insurance department ( $\bar{X}=66.74)$ and medical documentation and secretarial departments $(\bar{X}=65.68)$ respectively. ANOVA analysis showed a statistically significant difference in the computational thinking skill levels among these departments $(F(3,233)=3.810$, $p<.05)$.

When problem solving skill levels were examined according to departments, the department with the highest mean problem solving skill level $(\bar{X}=64.34)$ was found to be department of computer programming followed by medical documentation and secretarial department $(\bar{X}=62.93)$, first aid and emergency aid department $(\bar{X}=62,56)$ and banking and insurance department $(\bar{x}=62.49)$ respectively. Results of ANOVA analysis showed no statistically significant differences among these departments' computational thinking skills levels $(\mathrm{F}(3,233)=.643, p>.05)$.

As seen in the analysis, when students' logical mathematical intelligence levels were examined according to departments; the department with the highest mean logical mathematical intelligence level $(\bar{x}=68.28)$ was found to be first aid and emergency aid department followed by banking and insurance department $(\bar{X}=62.58)$, computer 
programming $(\overline{\mathrm{X}}=56.17)$ and medical documentation and secretarial department $(\bar{X}=52.72)$ respectively. Results of ANOVA analysis pointed to statically significant differences among departments' computational thinking skills levels $(F(3,233)=13.625$, $p<.01)$.

Another finding of the study showed a positive, medium level and significant relationship between students' Computational Thinking Skill levels and their Problem Solving Skills levels $(r=0.430 ; p<0.05)$. Also, a positive, medium level and significant relationship was identified between students' computational thinking skill levels and their logical mathematical intelligence levels $(r=0.522 ; p<0.05)$.

Finally, female students' computational thinking levels $(\bar{x}=67.68)$ was found to be lower than that of male students $(\overline{\mathrm{X}}=69.08)$. However, this difference was not identified as statistically significant $(\mathrm{t}(235)=1.152 ; p>0.05)$.

Discussion and Conclusions: According to the study results, departments' computational thinking levels were found to be different from one another. This difference was found statistically significant and students in the department of computer programming had the highest computational thinking skill levels. Department of computer programming is the only department among the participating departments in the study with training on computer programming. This result points to the importance of training students in programming to have them acquire computational thinking skills.

Another result found in the study showed that while problem solving skill levels differentiated according to departments, this difference was not statistically significant. Students in the department of computer programming had the highest problem solving skills levels among the participating departments. It can be argued that this difference was based on programming training that department of computer programming students received. Related studies also show that training on programming has positive impact on the development of problem solving skills.

The study reported statistically significant differences among departments in logical mathematical intelligence self-perceptions. There are similar studies in the literature that point to relationships between logical mathematical intelligence and academic achievement in mathematics.

A positive, medium level and significant relationship was identified between students' computational thinking skill levels and their problem solving skills levels. There are other studies which reported relationship between computational thinking and logical mathematical intelligence and problem solving skills.

Finally, the results pointed to differences in students' computational thinking skills levels in favor of male students; however, the difference was not statistically significant. Literature includes similar studies in which computational thinking skills did not statistically differ based on gender. 


\section{Kaynakça}

Akpınar, Y., \& Altun, A. (2014). Bilgi toplumu okullarında programlama eğitimi gereksinimi. Elementary Education Online, 13(1), 1-4.

Barr, D., Harrison, J., \& Conery, L. (2011). Computational thinking: A digital age. Learning \& Leading With Technology, 38(6), 20-23.

Barcelos, T., \& Silveira, I. (2012). Teaching computational thinking in initial series an analysis of the confluence among mathematics and computer sciences in elementary education and its implications for higher education. 2012 XXXVIII Conferencia Latinoamericana En Infermatica (CLEI) içinde (s. 1-8). Medellin, Colombia. DOI: 10.1109/CLEI.2012.6427135

Basu, S. (2016). Fostering synergistic learning of computational thinking and middle school science in computer-based intelligent learning environments (Unpublished doctoral dissertation). Submitted to the Faculty of the Graduate School of Vanderbilt University, Nashville, Tennessee

Bers, M., Flannery, L., Kazakoff, E., \& Sullivan, A. (2014). Computational thinking and tinkering: Exploration of an early childhood robotics curriculum. Computer \& Education, 72, 145-157.

Büyüköztürk, Ş., Kılıç Çakmak, E., Akgün, Ö., Karadeniz, Ş., \& Demirel, F. (2008). Bilimsel araştırma yöntemleri. Ankara: Pegem Akademi Yay.

Calder, N. (2010). Using scratch:An integrated problem-solving approach to mathematical thinking. Australian Primary Mathematics Classroom, 15(4), 914.

Chen, G., Shen, J., Barth-Cohen, L., Jiang, S., Huang, X., \& Eltoukhy, M. (2017). Assesing elemantary student' computational thinking in everyday reasoning and robotics programming. Computers \& Education, 109, 162-175.

Czerkawski, B., \& Lyman, E. (2015). Exploring issues about computational thinking in higher education. TechTrends, 59(2), 57-65.

Department For Education. (2013). Computing programmes of study: key stages 1 and 2 National curriculum in England. https://www.gov.uk/government/publications/national-curriculum-in-englandcomputing-programmes-of-study adresinden alınmıştır.

Doymuş, K., Şimşek, Ü., \& Bayrakçeken, S. (2004). İşbirlikçi öğrenme yönteminin fen bilgisi dersinde akademik başarı ve tutuma etkisi. Türk Fen Eğitim Dergisi, 1(2), 103-115.

Erden, M., \& Akman, Y. (2004). Gelişim ve öğrenme. (13. Baskı) Ankara: Arkadaş Yayınevi.

Fessakis, G., Gouli, E., \& Mavroudi, E,. (2013). Problem solving by 5 -6 years old kindergaten children in a computer programming environment: A case study. Computer \& Education, 63(1), 87-97.

Gonzalez, M., Gonzalez, J., \& Fernandez, C. (2016). Which cognitive abilities underlie computational thinking? Criterion validity of the computational thinking test. Computers in Human Behavior, 72, 1-14. 
Grover, S., \& Pea, R. (2013). Computational thinking in K-12: A review of the state of the field. Educational Researcher, 42(1), 38-43.

Gökçe, D., \& Atanur Başkan, G. (2012). Eğitim denetçilerinin iletişim becerileri. Hacettepe Üniversitesi Eğitim Fakültesi Dergisi, 42, 200-211.

Ioannou, I., \& Angeli, C. (2016). A Framework and an instructional design model for the development of students' computational and algorithmic thinking. Paper presented at the Tenth Mediterranean Conference on Information Systems, Paphos, $\quad$ Cyprus. https://pdfs.semanticscholar.org/e99d/a057a6241a0d85db9872f2dd0b50760e306b .pdf

ISTE. (2015). Computational thinking leadership toolkit first edition. Erişim adresi http://www.iste.org/docs/ct-documents/ct-leadershipt-toolkit.pdf?sfvrsn=4.

ISTE. (2016). ISTE standards for students. Erişim adresi http://www.iste.org/docs/Standards-Resources/iste-standards_students2016_one-sheet_final.pdf?sfvrsn=0.23432948779836327.

Karabak, D., \& Güneş, A. (2013). Curriculum proposal for first class secondary school students in the field of software development. Journal of Research in Education and Teaching, 2(3), 163-169.

Kayama, M., Satoh, M., Kobayashi, K., Kunimune, H., Hashimoto, M., \& Otani, M. (2014). Algorithmic thinking learning support syste based on student - problem score teble analysis. International Journal of Computer and Communication Engineering, 3(2), 134-140.

Koray, Ö., \& Azar, A. (2008). Ortaöğretim öğrencilerinin problem çözme ve mantıksal düşünme becerilerinin cinsiyet ve seçilen alan açısından incelenmesi. Kastamonu Ĕgitim Dergisi, 16(1), 125-136.

Korkmaz, Ö., Çakır, R., \& Özden, M. (2015). Bilgisayarca düşünme beceri düzeyleri ölçeğinin (BDBD) ortaokul düzeyine uyarlanması. Gazi Ĕ̆itim Bilimleri Dergisi, 1(2), 143-162.

Korkmaz, Ö., Çakır, R., Özden, M., Oluk, A., \& Sarığlu, S. (2015). Bireylerin bilgisayarca düşünme becerilerinin farklı değişkenler açısından incelenmesi. Ondokuz Mayls Üniversitesi Eğitim Fakültesi Dergisi, 34(2), 68-87.

Korkmaz, Ö., Çakır, R., \& Özden, M. (2017). A validity and reliability of the computational thinking scales (CTS). Computers in Human Behavior, 72, 1-43; doi:10.1016/j.chb.2017.01.005.

Korkut, F. (2002). Lise öğrencilerinin problem çözme becerileri. Hacettepe Üniversitesi Eğitim Fakültesi Dergisi, 23(23), 177-184.

Kurfiss, J. (1988). Critical thinking: Theory, Research, Practice, and Possibilities. ASHE-ERIC Higher Education Report No.2. Association For The Study Of Higher Education, Washington, DC.

León, J., \& Robles, G. (2015). Analyze your Scratch projects with Dr. Scratch and assess your computational thinking skills. Paper presented at the Scratch Conference, Amsterdam, The Netherlands. http://jemole.me/replication/2015scratch/InferCT.pdf 
Lu, J., \& Fletcher, G. (2009). Thinking about computational thinking. ACM SIGCSE Bulletin, 41(1), 260-264.

Liu, J., \& Wang, L. (2010). Computational thinking in discrete mathematics. In: IEEE Xplore Conference: 2nd International Workshop on Education Technology and Computer Science, . 413-416. doi:10.1109/ETCS.2010.200

MEB. (2017). Bilişim teknolojileri ve yazılım dersi öğretim programı. Erişim Tarihi: 12 Şubat 2017, http://mufredat.meb.gov.tr/Default.aspx

Mishra, P., \& Yadav, A. (2013). Of art and algorithms: rethinking technology \& creativity in the 21st centruy. TechTrends, 57(3), 10-14.

Ocak, M., \& Deveci Topal, A. (2010). Öğretimde yeni yaklaşımlar ve bilişim teknolojileri öğretimi. In S. Şahin (Ed.), Bilgisayar ve öğretim teknolojileri eğitimi özel ögretim yöntemleri I -II (ss. 139-169). Ankara: Pegem Akademi.

Olkun, S., Şahin, Ö., Akkurt, Z., Dikkartın, F., \& Gülbağcı, H. (2009). Modelleme yoluyla problem çözme ve genelleme: İlköğretim öğrencileriyle bir çalışma. Eğitim ve Bilim, 34(151), 65-73.

Oluk, A., \& Korkmaz, Ö. (2016). Comparing students' scratch skills with their computational thinking skills in terms of different variables. I.J. Modern Education and Computer Science, 8(11), 1-7.

Özden, Y. (2014). Öğrenme ve ögretme. Ankara: Pegem Akademi.

Özden, M. (2016). Computational thinking. Erişim adresi http://myozden.blogspot.com.tr/2015/06/computational-thinkingbilgisayarca.html.

Öztürk Can, H., Öner, Ö. İ., \& Çelebi, E. (2009). Üniversite öğrencilerinde eğitimin sorun çözme becerisine etkisinin incelenmesi. Firat Sağllk Hizmetleri Dergisi, 4(10), 35-58.

Plucker, J., Beghetto, R., \& Dow, G. (2004). Why isn’t creativity more important to educational psychologists? potentials, pitfalls, and future directions in creativity research. Educational Psychologist, 39(2), 83-96.

Shin, S., Park, P., \& Bae, Y. (2013). The effects of an information-technology gifted program on friendship using scratch programming language and clutter. International Journal of Computer and Communication Engineering, 2(3), 246249.

Sümbül, A. (2007). Öğretim ilke ve yöntemleri. Konya: Çizgi Kitabevi.

The Collage Board. (2016). AP Computer science principles including the curriculum framework. Erişim Tarihi: 12 Kasım 2016, https://securemedia.collegeboard.org/digitalServices/pdf/ap/ap-computer-science-principlescourse-and-exam-description.pdf

Timuçin, E. (2010). Bilişim teknolojileri öğretim yöntemleri. In S. Şahin (Ed.), Bilgisayar ve ögretim teknollojileri ĕgitimi özel ögrretim yöntemleri I-II (ss. 99135). Ankara: Pegem Akademi.

Taylan, S. (1990). Heppner'in problem çözme envanterinin uyarlama, güvenirlik ve geçerlik çalışmaları (Yayınlanmamış Yüksek Lisans Tezi). Ankara Üniversitesi Sosyal Bilimler Enstitüsü, Ankara. 
Yadav, A., Hong, H., \& Stephenson, C. (2016). Computational thinking for all: Pedagogical approaches to embedding 21st century problem solving in K-12 clasrooms. Tech Trends, 60(6) 565-568, DOI 10.1007/s11528-016-0087-7.

Yadav, A., Mayfield, C., Zhou, N., Hambrusch, S., \& Korb, J. (2014). Computational thinking in elementary and secondary teacher education. ACM Transactions on Computing Education, 14(1), 1-5.

Yadav, A., Zhou, N., Mayfield, C., Hambrusch, S., \& Korb, J. (2011). Introduction computational thinking in education courses. 42nd ACM Technical Symposium on Computer Science Education. ACM, Texsas, USA

Yeşil, R., \& Korkmaz, Ö. (2010). Reliability and validity analysis of the multiple intelligence perpection scale. Education, 131(1), 8-32.

Voogt, J., Fisser, P., Good, J., Mishra, P., \& Yadav, A. (2015). Computational thinking in compulsory education: Towards an agenda for research and practice. Educ Inf Techno, 20(2015), 715-728.

Veenman, S., Benthum, N., Bootsma, D., Dieren, J., \& Kemp, N. (2002). Cooperative learning and teacher education. Teaching and Teacher Education, 18, 87-103.

Wing, J. (2006). Computational thinking. Commun. Communications of the ACM, 49(3), 33-35.

Wing, J. (2008). Computational thinking and thinking about computing. Philosophical Transactions of th Royal Society A: Mathematical, Physical and Engineering Sciences, 366, 3717-3725.

Wing, J. (2010). Computational thinking: What and why? Erişim adresi http://www.cs.cmu.edu/ CompThink/resources/TheLinkWing.pdf. 